\title{
PREVENTION OF POST OPERATIVE INFECTIONS IN EMERGENCY CAESAREAN SECTIONS: ROLE OF SURGICAL BUNDLE AND VAGINAL CLEANING
}

KEY WORDS:

Dr. Asma Nagori

\section{Dr. Deeba} Khanam*

\section{Prof. Shaheen}

M.S Obs and Gynae, dept of Obs and Gynae,Jawahar Lal Nehru Medical college,AMU Aligarh Rifa apartment, medical road Aligarh.

M.S Obs and Gynae, dept of Obs and Gynae,Jawahar Lal Nehru Medical college,AMU Aligarh .R/O Ali cottage, shaukat manzil ,dodhpur Aligarh 202002. *Corresponding Author

M.S Obs and Gynae, dept of Obs and Gynae,Jawahar Lal Nehru Medical college,AMU Aligarh,R/O Kela nagar Aligarh

M.S Microbiology, dept of Obs and Gynae,Jawahar Lal Nehru Medical college,AMU Aligarh,R/O Kela nagar Aligarh

Prof. Meher Rizvi

Introduction: Caesarean section (CS) is one of the commonest surgical procedures performed in obstetrics. Postoperative infectious complications including surgical site infections (SSI) are a cause of significant morbidity after CS as compared to vaginal delivery.

Aim: To assess the role of application of surgical bundle and vaginal cleaning before caesarean section in preventing postoperative infectious complications.

Design: Prospective randomised interventional study.

Place and duration of study: Department of Obstetrics and Gynaecology, Jawaharlal Nehru Medical College and hospital, Aligarh from November 2016 to October 2018

Methodology: Total of 216 patients undergoing emergency CS in the hospital was enrolled in the study. Patients were kept in 2 groups. In group 1, women undergoing emergency C-Section whom conventional preoperative preparation was done using savlon-povidone iodine as skin antiseptic and a 7 day postop prophylactic antibiotic regime was administered. In group 2, surgical bundle and vaginal cleaning was done but postop prophylactic antibiotic regime was reduced to 3 day

Results: Overall, SSIs were most common infectious morbidity in both groups with highest incidence in group 1(14.7\%) and lower in group 2(7.01\%), and the difference was statistically significant. Rates of endometritis, UTI and URTI were similar among 2 groups. Duration of hospital stay was lower for group 2 (6.43+_3.29days). No Significant association was noted between haemoglobin levels $<8 \mathrm{~g} / \mathrm{dl}$ and number of $>4$ vaginal examinations with risk of development of SSI $(\mathrm{p}<0.05)$

Conclusion: Bundled approach including vaginal cleaning has decreased the incidence of SSIs after emergency CS but larger clinical studies are needed to prove the definite role.

\section{INTRODUCTION}

Caesarean section (CS) is one of the most common surgical procedures performed in obstetrics. Despite of its implications there has been an unprecedented rise in the incidence of this procedure worldwide in the last few decades.

Postoperative complications are a cause of significant maternal and fetal morbidity after CS. Overall maternal morbidity rates increase twofold with caesarean delivery, mainly due to infection, haemorrhage, thromboembolism and adjacent organ injury ${ }^{1}$.Infectious complications contribute to 5-20 fold increase following caesarean delivery as compared to vaginal delivery ${ }^{2-6}$ with fever, endometritis, wound infection and UTI as the major contributors ${ }^{7,8}$

Surgical site infections (SSI), which occur in the wound created by any invasive surgical procedure reflects an important cause of infectious morbidity. Thus, post caesarean SSI is common in obstetrical scenarios, specifically in emergency caesareans ${ }^{9}$. These infections affect a woman's physical and mental health and so all preventive measures should be directed to improve a woman's quality of life.

Surgical site infections are graded as superficial, deep and organ and space infection. Superficial infections include skin and subcutaneous tissue; deep infections include fascia and muscular layer. Organ and space infection constitute the one in which any organ or space is infected.

Risk reduction of SSI post-surgery is of prime concern and so multiple evidence-based interventions were proposed by the
Institute of Healthcare Improvement (IHI) known as care bundles. Care bundles are collective and systematic strategies implemented to prevent SSI with potential to improve patient outcome. Individual intervention may vary between different bundles but success depends on application of all measures consistently and persistently in a bundle. Optimal care bundle includes maintaining normothermia, glycaemic control, timely and appropriate administration of antibiotic and clipping of hair. These are the core elements of care bundle and apart from it further additions can be made which may be synergistic or neutral.

With the view of reducing SSI we planned a study to assess the role of application of surgical bundle and vaginal cleaning with antiseptic solution in prevention of postoperative infectious morbidities after emergency CS.

\section{MATERIALS AND METHOD}

This was a prospective randomized interventional study, conducted in the Department of Obstetrics and Gynaecology, Jawaharlal Nehru Medical College and Hospital, Aligarh from November 2016 to October 2018. Patient selection was based on following criteria:

\section{INCLUSION CRITERIA}

- Patients undergoing emergency caesarean section with no recent injury or active infection in the area being operated.

\section{EXCLUSION CRITERIA}

- Patients with history of allergy to antimicrobial agent.

- Patients requiring dose adjustment of antibiotic- chronic 
renal disease or liver disease or any other medical comorbidity.

- Patients having chorioamnionitis or any other preoperative infectious disease at time of making decision of caesarean section.

- Patients had any other surgical procedure requiring spinal anaesthesia or general anaesthesia within 1 month prior to caesarean section.

Total of 216 patients were enrolled and were kept in 2 groups made over consecutive periods of 6 months with reduction of number of days of prophylactic antibiotics.

Group 1 (102 ): women undergoing emergency CS on whom only conventional preoperative preparation was done using savlon-povidone iodine as skin antiseptic and a 7-day postop prophylactic antibiotic regime was administered.

Group 2 (114): surgical bundle and vaginal cleaning was done postoperatively prophylactic antibiotic regime was reduced to 3 days.

Surgical bundle consisted of intravenous antibiotic administration 15-60 min prior to skin incision, hair clipping in those who required, skin prepping using $2 \%$ chlorhexidine gluconate solution, vaginal cleaning with povidone iodine and maintenance of normothermia and euglycemia intra- and post operatively.

All patients were examined daily during hospitalization. In presence of adequate wound healing and absence of signs and symptoms of any infection, patients were discharged from hospital on day 4 or day 5 . Stitch removal was done on day 9 or day 10 . Subsequently patients were examined after 6 weeks postpartum.

In presence of any clinical features suggestive of an infectious morbidity, patients were examined for presence of fever, urinary tract infections (UTI), upper respiratory tract infection (URTI), wound discharge, induration or dehiscence, endometritis and pelvic abscess. SSIs were classified according to CDC criteria. Further investigations and appropriate management was done accordingly.

Rates and types of infectious complications were noted and data was entered into Excel and cleaved, then transferred to SPSS version 25 for analysis. Descriptive statistics was done by percentages and mean \pm SD and inferential statistics was applied using chi square and fisher exact test. P-value $<0.05$ was considered significant.

\section{RESULTS}

The prospective study was carried out on 216 patients who underwent emergency CS. All were randomised in 2 study groups. Both the groups were similar with respect to distribution of age, gravidity, socioeconomic status, OPD booking status, BMI, haemoglobin levels, time of rupture of membranes and indications of CS ( $p>0.05)$.

In our study, most common infection was SSI (table 1) with incidence of $15.70 \%$ in Group 1, and $7.01 \%$ in Group 2. The infection was lower in Groups 2 in which care bundle was applied as compared to Group 1, the difference was statistically significant. Febrile morbidity (fever $>100.4 \mathrm{~F}$ ) occurred in $9.80 \%$ in Group 1, $4.38 \%$ in Group 2. The febrile morbidity was lower in Group 2, as compared to Group 1 however, the difference was statistically insignificant in both the groups. Rates of endometritis, UTI and URTI remained almost similar.

Regarding CDC category of SSI (table 2), most frequent were superficial incisional SSI with incidence of $6.14 \%$ in Group 2 and $13.74 \%$ in Group 1. The difference was, however, not statistically significant. The incidence of SSI, mainly superficial incisional SSI and febrile morbidity was lower in Group 2 which was given 3 day antibiotic post-operatively as compared to Group 1 in which 7-day antibiotic was given.

Table 1- showing incidence of infectious complications in different study groups

Table No. 1: Incidence Of Infectious Morbidities

\begin{tabular}{|c|c|c|c|c|c|}
\hline & \multicolumn{2}{|c|}{ Group $1 \mathrm{~N}=102$} & \multicolumn{2}{|c|}{ Group $2 \mathrm{~N}=114$} & \multirow[t]{2}{*}{$P$ value } \\
\hline & number & $\%$ & number & $\%$ & \\
\hline fever & 10 & 9.8 & 5 & 4.3 & 0.117 \\
\hline SSI & 16 & 15.6 & 8 & 7.0 & 0.042 \\
\hline Endo & 1 & 0.9 & 1 & 0.8 & 0.936 \\
\hline UTI & 2 & 1.9 & 2 & 1.7 & 0.910 \\
\hline URTI & 2 & 1.9 & 1 & 0.8 & 0.496 \\
\hline
\end{tabular}

Table No.2: Incidence Of Different Types Of Ssi

\begin{tabular}{|c|c|c|c|c|c|}
\hline & \multicolumn{2}{|c|}{ Group $1 \mathrm{~N}=102$} & \multicolumn{2}{|c|}{ Group $2 \mathrm{~N}=114$} & \multirow[t]{2}{*}{ P value } \\
\hline & number & $\%$ & number & $\%$ & \\
\hline Superficial & 14 & 13.7 & 7 & 6.1 & 0.06 \\
\hline Deep & 1 & 0.9 & 0 & 0 & - \\
\hline Organ specific & 1 & 0.9 & 1 & 0.8 & - \\
\hline
\end{tabular}

Most common presentation of SSI was purulent discharge from wound which occurred in $85.3 \%$ of patients. Maximum number of infections were noted on post-operative day 5 and day 6.Most common pathogen isolated from pus culture swab from surgical wound was Staphylococcus aureus (36.5\%)including 4 cases of MRSA followed by Citrobacter species.

Most patients in both the Groups were discharged within 10 days. Lowest average duration of hospital stay was $6.43 \pm 3.29$ days, noted in Group 2.

Table 3: Incidence Of Various Infectious Morbidities According To No. OfVaginal Examination

\begin{tabular}{|l|l|l|l|l|}
\hline \multirow{2}{*}{} & \multicolumn{2}{|l|}{ Group 1 N=102 } & \multicolumn{2}{l|}{ Group 2 N=114 } \\
\cline { 2 - 5 } & $<4 \mathrm{pv}$ & $>4 \mathrm{pv}$ & $<4 \mathrm{pv}$ & $>4$ \\
\hline SSI & 5 & 11 & 1 & 7 \\
\hline Endometritis & 0 & 1 & 0 & 1 \\
\hline Fever & 4 & 6 & 2 & 3 \\
\hline UTI & 0 & 2 & 0 & 2 \\
\hline URTI & 0 & 2 & 0 & 1 \\
\hline
\end{tabular}

In our study, significant association between haemoglobin levels $<10 \mathrm{~g} / \mathrm{dl}$ and $>4$ vaginal examinations (tables $3 \& 4$ ) was not noted although the infectious morbidities were more in the group with decreased $\mathrm{Hb}$ levels and greater than 4 per vaginal examinations. No association was observed with specific age group, booking status, socio-economic class, BMI and time of ruptured membranes $(\mathrm{p}>0.05)$.

Table 4: Incidence Of Infectious Morbidity According To Haemoglobin Level

\begin{tabular}{|l|l|l|l|l|}
\hline \multirow{3}{*}{} & \multicolumn{2}{|l|}{ Group 1 N=102 } & \multicolumn{2}{l|}{ Group 2 N=114 } \\
\cline { 2 - 5 } & No. & $\%$ & No. & $\%$ \\
\cline { 2 - 5 } & $6-9.9$ & $\geq 10$ & $6-9.9$ & $\geq 10$ \\
\hline SSI & 10 & 6 & 6 & 2 \\
\hline Endometri & 1 & 0 & 1 & 0 \\
\hline Fever & 7 & 3 & 3 & 2 \\
\hline UTI & 2 & 0 & 2 & 0 \\
\hline URTI & 2 & 0 & 1 & 0 \\
\hline
\end{tabular}

\section{DISCUSSION}

Post-operative infectious morbidity varies in incidence due to difference in population characteristics, associated risk factors, proper use of preoperative procedures and adequate post op surveillance for SSI and other sources of infections.

Among all known practices, application of surgical bundle has considerably affected the incidence of SSI ${ }^{10}$. Use of single dose prophylactic antibiotic is recommended by WHO as a 
part of care bundle ${ }^{11}$. Injudicious use of antibiotics is practiced among $25-50 \%$ of cases, in the form of overuse or underuse. ${ }^{12}$.

In our study we created 2 groups where on one end a group was formed where along with surgical bundle post op antibiotic was given for 7 days and the other group had all the core elements of surgical bundle with a 3 day post op antibiotic course with vaginal cleaning.

Incidence of febrile morbidity was $9.8 \%$ in Group $1,4.3 \%$ in Group 2, which was lower in comparison to the first group.

Incidence of SSI, in our study, was 15.6\% in Group 1, 7.01\% in Group 2 which was statistically significant.RonghuaLiet al in a study with 7 day post op antibiotic similar to group 1 suggested SSI rate of $8 \%{ }^{13}$ A study conducted in Telangana ${ }^{14}$ reported $9.18 \%$ incidence of SSI, after emergency caesarean section in which post-operative antibiotics were given for 7 days. Clayton et $\mathrm{al}^{15}$ in their study compared the rate of SSI after 3 day vs lday post op antibiotic and found the rates lower in the first group.

To prevent the infection from establishing there is a decisive period when the defence system of the body tries to contain the infection, and interventions post that period is of little benefit to the patient. Presence of minimum inhibitory concentration of antibiotic in the tissues at the time of invasion of the bacteria is required and so preoperative antibiotic prophylaxis plays crucial role. Post operatively how long the antibiotics should be continued is debatable

In this study we have tried to compare the effectiveness of the two regimens that is 7-day vs 3-day antibiotic course in preventing post op infections. Our results clearly suggest that 3-day antibiotic regimen is better at preventing SSI in concordance with few studies conducted to compare benefits of prolongation of antibiotic course ${ }^{15,16,17}$ which concluded no added benefit.

In our study, superficial incisional SSI was more common in both the groups. The incidence of deep incisional SSI and organ SSI (endometritis) was less than 1\% in groupl and no patient developed deep incisional SSI or endometritis in Group 2.A study conducted to evaluate the role of antibiotic prophylaxis suggested preoperative prophylaxis to be the most beneficial irrespective of the duration of post op antibiotic in preventing endometritis. ${ }^{18}$.Despite the duration and timing of antibiotics the risk of SSI and endometritis still persists and therefore in addition to antibiotic prophylaxis vaginal cleaning with the help of povidone iodine or chlorohexidine solution can further reduce the chances of these post op infections as it reduces the bacterial load in the genital tract ${ }^{19}$.In our study we used vaginal prepration with povidone iodine in second group in addition to 3 day antibiotic course, and the incidence of endometritis was lower than first group but not statistically significant. Another study showed significant reduction in incidence of endometritis post vaginal prepration. ${ }^{20}$. Mady et al showed significant reduction in endometritis with almost no effect on fever and SSI ${ }^{21}$.Thus vaginal prepration should be included in preop procedures to reduce post op infections mainly endometritis.

Certain other parameters were included in the study to assess their impact on post op infections In the present study, significant association was noted between haemoglobin levels $<10 \mathrm{~g} / \mathrm{dl}$ and $>4$ vaginal examinations in both the groups separately with risk of development of SSI $(p<0.05)$. No association was observed with specific age group, booking status, socio-economic class, BMI and time of ruptured membranes $(p>0.05)$. These findings were supported in other studies ${ }^{14,17-19}$.

\section{CONCLUSION}

Infectious morbidities after CS impose a major women health challenge. It is important to prevent these complications by implementing appropriate measures. Present study shows that application of surgical bundle with 3 day postoperative antibiotic regimen and vaginal cleaning can reduce postop infectious complications. Prolonging the duration of antibiotics post operatively does not provide any added benefit but on contrary can lead to increased bacterial resistance, increased hospital stay and increased economic burden.Further vaginal cleaning has proven benefits in reducing post op infections which is supported by our study. Further trials are required to assess the necessity of 3 day antibiotic regimen and its effectiveness to reduce infectious morbidities.

\section{REFERENCES}

1. Cunningham F, Leveno K, Bloom S, Spong CY, Dashe J. Williams obstetrics, 25e. Mcgraw-hill; 2018.11 Declercq E, Barger M, Cabral HJ, Evans SR, Kotelchuck

2. Simon C, et al. Maternal outcomes associated with planned primary cesarean births compared with planned vaginal births. Obstet Gynecol 2007; 109: 669-77.12 Gibbs

3. RS. Clinical risk factors for puerperal infection. ObstetGynecol 1980;55(5 Suppl):178s-84s.

4. Fry DE. Surgical site infections and the surgical care improvement project (SCIP): evolution of national quality measures. Surgical infections. $2008 \mathrm{Dec}$ $1 ; 9(6): 579-84$.

5. Bärwolff S, Sohr D, Geffers C, Brandt C, Vonberg RP, Halle H, Rüden H, Gastmeier P. Reduction of surgical site infections after Caesarean delivery using surveillance. Journal of Hospital Infection. 2006 Oct 1;64(2):156-61.

6. Mitt P, Lang K, Peri A, Maimets M. Surgical-site infections following cesarean section in an Estonian university hospital: postdischarge surveillance and analysis of risk factors. Infection Control \& Hospital Epidemiology. 2005 May;26(5):449-543

7. Leigh DA, Emmanuel FX, Sedgwick J, Dean R. Post-operative urinary tract infection and wound infection in women undergoing caesarean section: a comparison of two study periods in 1985 and 1987. J Hosp Infect 1990;15:107-16.

8. MacLean AB. Clinical Infection in Obstetrics and Gynaecology. Oxford: Blackwell Scientific, 1990.15 Owen J, AndrewsWW.Wound co.

9. Koroukian SM. Relative risk of postpartum complications in the Ohio Medicaid population: vaginal versus cesarean delivery. Medical Care Research and Review. 2004 Jun;61 (2):203-24.

10. The American College of Obstetricians and Gynecologists (2010) ACOG committee opinion no 465: antimicrobial prophylaxis for cesarean delivery: timing of administration. Obstetrics \&Gynecology 116,791-792.

11. Villar J et al. World Health Organization 2005 Global Survey on Maternal and Perinatal Health Research Group (2007) Maternal and neonatal individual risks and benefits associated with caesarean delivery: multicentre prospective study. British Medical Journal 335, 1025.

12. Kasatpibal N, Jamulitrat S and Chongsuvivatwong V (2005) Standardized incidence rates of surgical site infection: a multicenter study in Thailand. American Journal of Infection Control 33,587-594.

13. Ronghua liu, lin lin and dujuan wang experimental and therapeutic medicinel2:961-964,2016J

14. OralMaxillofacSur 2017Apr;75(4):796804.doi:10.1016/j.joms.2016.09.038. Epub2016 Oct 3.

15. Togo S, Tanaka K, Matsuo K, Nagano Y, Ueda M, Morioka D, et al. Duration of antimicrobial prophylaxis in patients undergoing hepatectomy: a prospective randomized controlled trial using flomoxef. J Antimicrob Chemother2007;59:96

16. Gupta A, Hote MP, Choudhury M, Kapil A, Bisoi AK. Comparison of $48 \mathrm{~h}$ and 72 $h$ Of prophylactic antibiotic therapy in adult cardiac surgery: a randomizedouble blind controlled trial. J Antimicrob Chemother. 2010;65:1036-41. [PubMed]

17. Sawyer R, Cozzi L, Rosenthal DI, Maniglia AJ. Metronidazole in head and neck surgery--the effect of lengthened prophylaxis. Otolaryngol Head Neck Surg. 1990;103:1009-11.[PubMed] Obstet Med.2014 Sep; 7(3):98-102.

18. EDalton ${ }^{1}$ and E Castillol,2Published online $2014 \mathrm{Feb}$

19. Haas DM, Morgan S, Contreras K, Kimball S. Vaginal preparation with antiseptic solution before cesarean section for preventing postoperative infections. Cochrane Database of Systematic Reviews 2020, Issue 4. Art. No. infections. Cochrane Database of Systematic Reviews

20. Ahmed MR, Aref NK, Sayed Ahmed WA, Arain FR. Chlorhexidine vaginal wipes prior to elective cesarean section: does it reduce infectious morbidity? A randomized trial. J MaternFetal Neonatal Med. 2017;30(12): 1484-1487.doi:10.1080/14767058.2016.1219996

21. Yokoe DS, Christiansen CL, Johnson R, Sands KE, Livingston J, Shtatland ES, Platt R. Epidemiology of and surveillance for postpartum infections. Emerging infectious diseases. 2001 Sep;7(5):837.

22. Vijaya K, Padmaja A, Poreddy A,Vivekanand N. Research Article Surgical Site Wound Infection in Emergency and Elective LSCS-A Comparative Study. Emergency.;3489(36):1-03.

23. Provonost $\mathrm{P}$, Needham $\mathrm{D}$, Berenholtz $\mathrm{S}$, et al. An intervention to decrease catheter related bloodstream infections in the ICU. N Engl J Med 2006;355:2725-32.

24. Resar R, Pronovost P, Haraden C, et al. Using a bundle approach to improve ventilator care processes and reduce ventilator-associated pneumonia. Jt Comm J Qual Patient Saf2005;31:243-8.

25. Ahmed ET, Mirghani OA, Gerais AS, Adam I. Ceftriaxone versus ampicillin/cloxacillin as antibiotic prophylaxis in elective caesarean section. East Mediterr Health J.2004 May;10(3):277-88. 
26. von Mandach U, Huch R, Malinverni R, Huch A. Ceftriaxone (single dose) versus cefoxitin (multiple doses): success and failure of antibiotic prophylaxis in 1052 cesarean sections. Journal of Perinatal Medicine-Official prophylaxis in 1052 cesarean sections.
Journal of the WAPM. 1993;21(5):385-97.

27. Jakobi P, Weissman A, Zimmer EZ, Paldi E. Single-dose cefazolin prophylaxis for cesarean section. American Journal of Obstetrics \&Gynecology. 1988 May 1;158(5):1049-52.

28. Alekwe, L. O., Kuti, O., Orji, E. O., and Ogunniyi, S. O. (2008). Comparison of ceftriaxone versus triple drug regimen in the prevention of cesarean section infectious morbidities. J. Matern. Fetal. Neonatal Med. 21, 638-642. doi: 10.1080/14767050802220490

29. Vijaya K, Padmaja A, Poreddy A, Vivekanand N. Research Article Surgical Site Wound Infection in Emergency and Elective LSCS-A Comparative Study. Emergency.;3489(36):1-03.

30. Wloch C, Wilson J, Lamagni T, Harrington P, Charlett A, Sheridan E. Risk factors for surgical site infection following caesarean section in England: results from a multicentre cohort study. BJOG: An International Journal of Obstetrics \& Gynaecology. 2012 Oct;119(11):1324-33.

31. Vallejo MC, Attaallah AF, Shapiro RE, Elzamzamy OM, Mueller MG, Eller WS Independent risk factors for surgical site infection after cesarean delivery in a rural tertiary care medical center. Journal of anesthesia. $2017 \mathrm{Feb}$ $1 ; 31(1): 120-6$.

32. Ezechi OC, Edet A, Akinlade H, Gab-Okafor CV, Herbertson E. Incidence and risk factors for caesarean wound infection in Lagos Nigeria. BMC Research Notes.2009 Dec;2(1):186.

33. Bizimana K, Ndoli J, Bayingana C, Baluhe I, Gilson GJ, Habimana E. Prevalence and risk factors for post cesarean delivery surgical site infection in a teaching hospital setting in rural Rwanda: A prospective cross sectional study. International Journal of Current Microbiology and Applied Sciences. 2016;5(6):631-41.

34. Talukdar DR. Surgical Site Infection Following Emergency LSCS-to Find out the Incidence, Risk Factors and Commonly Associated Bacteria. Scholars J Appl Med Sci. 2015;3(8A):2794-801. 